\title{
Despite COVID-19, Data Support Kangaroo Care
}

Michelle Winokur, DrPH, and the AfPA Governmental Affairs

Team, Alliance for Patient Access (AfPA)

The Alliance for Patient Access (allianceforpatientaccess.org), founded in 2006, is a national network of physicians dedicated to ensuring patient access to approved therapies and appropriate clinical care. AfPA accomplishes this mission by recruiting, training and mobilizing policy-minded physicians to be effective advocates for patient access. AfPA is organized as a non-profit 501(c)(4) corporation and headed by an independent board of directors. Its physician leadership is supported by policy advocacy management and public affairs consultants. In 2012, AfPA established the Institute for Patient Access (IfPA), a related 501(c) (3) non-profit corporation. In keeping with its mission to promote a better understanding of the benefits of the physician-patient relationship in the provision of quality healthcare, IfPA sponsors policy research and educational programming.

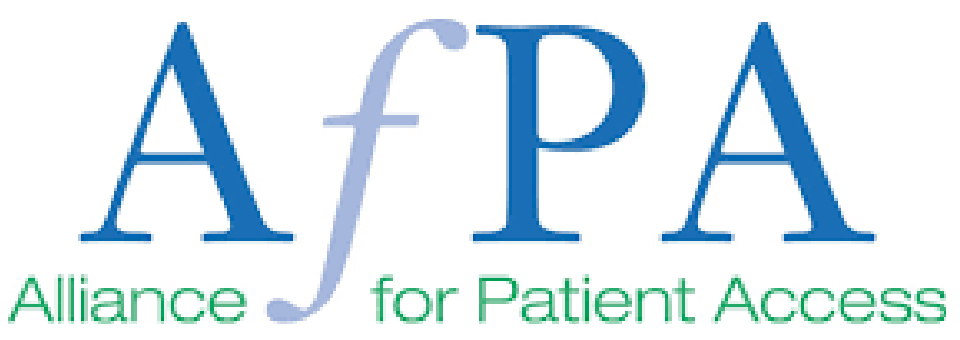

According to a global survey, more than $85 \%$ of neonatal health care personnel feared for their own health while working during COVID-19. (1) Inadequate or erratic availability of personal protective equipment, such as masks and gloves, was chief among providers' anxieties. Staff shortages and longer shifts increased providers' stress.

\section{"According to a global survey, more} than $85 \%$ of neonatal health care personnel feared for their own health while working during COVID-19. (1) Inadequate or erratic availability of personal protective equipment, such as masks and gloves, was chief among providers' anxieties. Staff shortages and longer shifts increased providers' stress."
"The worst-case scenario, assuming $100 \%$ transmission, could result in 1,950 neonatal deaths, they found. (3) In contrast, they estimated more than 125,000 newborn lives would be saved if kangaroo care was practiced universally."

Now, details about how those sentiments have changed the practice of maternal and neonatal medicine are coming to light.

According to the survey, two-thirds of healthcare providers would not support "kangaroo care" with mothers who had a positive or unknown COVID-19 status. The technique involves prolonged skin-to-skin contact and exclusive breastfeeding. It is an evidencebased best practice for small and sick newborns. World Health Organization guidelines strongly recommend initiating kangaroo care for all newborns weighing 2,000 grams or less as soon as the baby is clinically stable. (2)

Instead of following this guidance, however, some health care providers separated babies from their mothers to reduce COVID-19 exposure. In separating babies from their mothers, health care providers inadvertently traded one risk for another, more serious one.

A team of researchers from the WHO, London School of Hygiene \& Tropical Medicine, and the University of California San Francisco modeled scenarios in which a COVID-19-infected mother would transmit the virus to her infant. The worst-case scenario, assuming $100 \%$ transmission, could result in 1,950 neonatal deaths, they found. (3) In contrast, they estimated more than 125,000 newborn lives would be saved if kangaroo care was practiced universally.

Study authors concluded infants had at least a 65-fold increase in death risk by not doing kangaroo care. The risk of virus transmission, they cautioned, cannot be mitigated completely, although "infection prevention and control practices have been shown to reduce that risk considerably."

In short, COVD-19 separation policies have harmed newborns. Warned the authors: "Since the start of the COVID-19 pandemic ... coverage and quality of maternal and neonatal care has deteriorated."

It behooves babies - and their mothers - for health systems to reevaluate precautionary policies that curtail parental closeness on account of coronavirus exposure. Kangaroo care, even if the mother is COVID-19 positive, is in the baby's best interest. Models have shown the benefits of kangaroo care far outweigh the risk of COVID-19 mortality.

As the world starts to look toward a life beyond COVID-19, patients, providers, and policymakers would do well to keep the pandemic's lessons top of mind. Deterring from long-standing, evidence-based care does not often turn out well, even when it is driven by the best of intentions.

\section{References}


1. Rao SPN, Minckas N, Medvedev MM on behalf of the COVID-19 Small and Sick Newborn Care Collaborative Group, et al. Small and sick newborn care during the COVID-19 pandemic: global survey and thematic analysis of healthcare providers' voices and experiences. BMJ Global Health 2021;6:e004347.

2. WHO. Recommendations on interventions to improve preterm birth outcomes. Geneva; 2015. [cited 2021 Apr 7]. Available from: http://apps.who.int/iris/bitstre am/10665/183037/1/9789241508988 eng.pdf.

3. Minckas N, Medvedev MM, Adejuyigbe EA, Brotherton $H$, Chellani $H$, Estifanos AS et al. Preterm care during the COVID-19 pandemic: A comparative risk analysis of neonatal deaths averted by kangaroo mother care versus mortality due to SARS-CoV-2 infection. The Lancet 2021; 33:100733. DOI:https://doi.org/10.1016/j.eclinm.2021.100733

Michelle Winokur, DrPH, is the Policy Communications Director for the Alliance for Patient Access.

Disclosures: none

NT

Corresponding Author
Michelle Winokur, DrPH,
Policy Communications Director
Alliance for Patient Access (AfPA) Government Affairs Team
1275 Pennsylvania Ave. NW, Suite 1100A Washington, DC
20004-2417
202-499-4114
info@allianceforpatientaccess.org

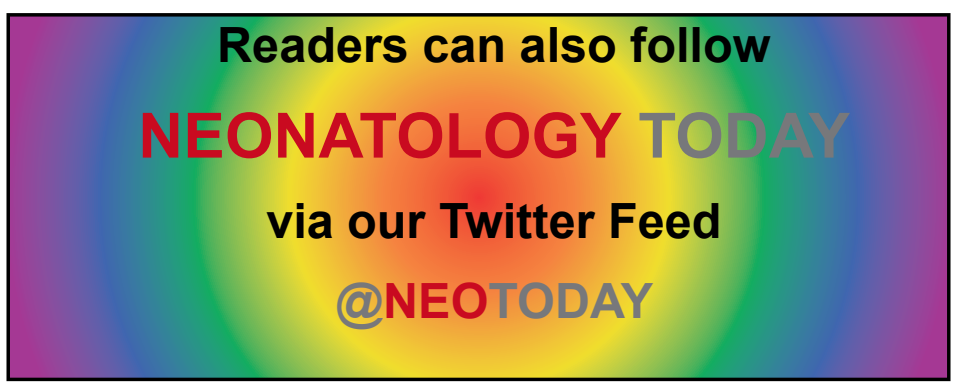

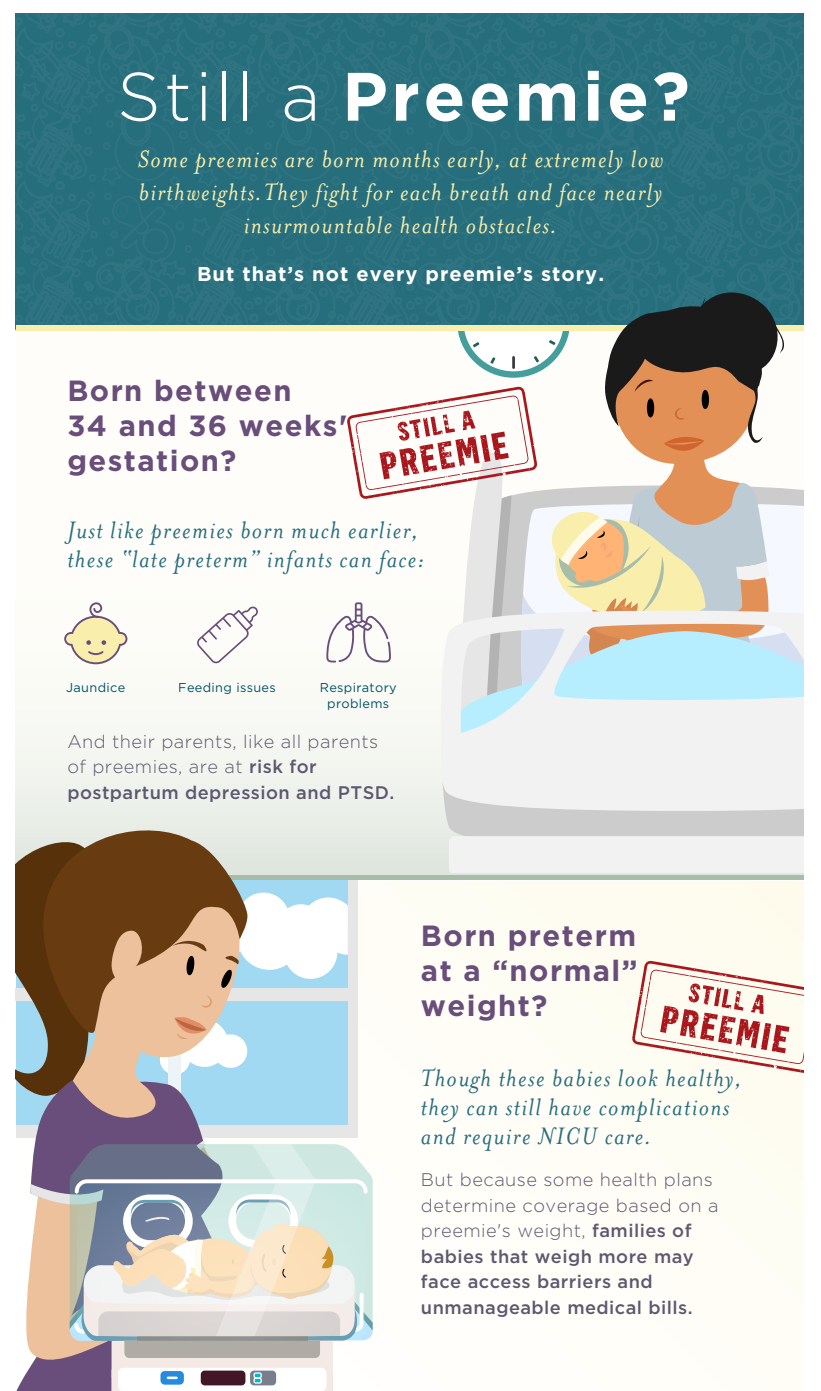

Born preterm but not admitted to the NICU?

Even if preterm babies don't require NICU care, they can still face health challenges.

Those challenges can extend through childhood, adolescence and even into adulthood.
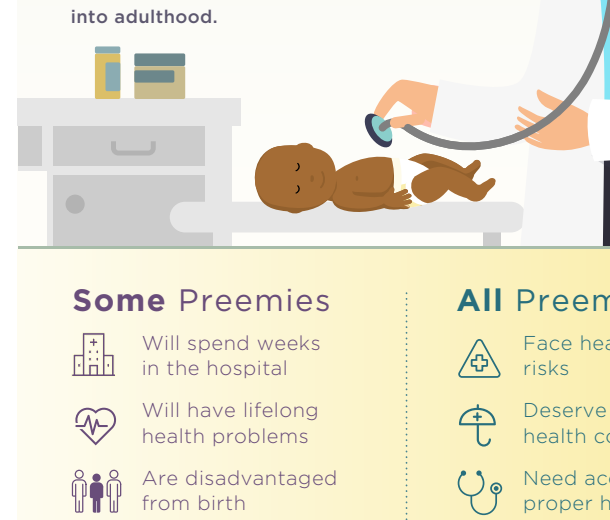

All Preemies

Face health \$ risk $\oplus$ Deserve appropriate $\smile$ health coverage Uo Need access to proper health care 